\title{
Fazıl Hüsnü Dağlarca Şiirinde Mistisizm ve Sezgi ${ }^{1}$

\author{
Kemal ŞAMLIOĞLU \\ Dr., Ankara Hacı Bayram Veli Üniversitesi \\ ksamlioglu@hbv.edu.tr
} \\ Orcid ID: https://orcid.org/0000-0003-4765-5592
}

\begin{abstract}
Öz
Batılılaşmanın önemli kavşak noktalarından biri olan Tanzimat süreci aydın profilin edebiyatçı kimliğiyle kendini sunmasının da zeminini oluşturur. Yüzyıllardır nesilden nesle aktarılan değerlerin yaşadığı kriz, edebiyat sahasına da sirayet etmiş, Tanzimat aydınındaki zihin bulanıklığı başta şiir olmak üzere edebiyat anlayışını da müphemleştirmiştir. Söz konusu müphemlik Batı'nın Doğu üzerindeki tahakküm araçlarından birinin edebiyat oluşundan kaynaklanır. Tanzimat aydını yeni, modern ve çağdaş gördügü Fransız şiirine yönelirken geleneksel şiirden kolay vazgeçemeyecektir. Batı'dan yeni epistemik alan yüklemeleri yapılırken gelenekten de kendi kavramlarını koruyacak bir direnç alanı oluşur. Bütün bunlar yaşanırken Batı'ya özgü değerleri sahiplenmek belli düzeyde pozitivist bir refleksle ortaya çıar, geleneği savunmak da onun karşı ucunda yer alan mistisizme sığınma refleksiyle kendini gösterir. İslâmî düşünceye ait kavramlar şiir geleneği üzerinden dağılırken Tanzimat aydınında bu durumun varlığı modern düşünüş tarzına uygun yeni kavramların kapısını aralar. Cumhuriyet dönemine gelindiğinde bu durum, kaynağına dönüş problemi olarak karşımıza çıkar. Modernitenin verileriyle problem yaşayan aydın, varoluşsal değerlere tekrar yönelim gösterir.

Tanzimat'la başlayan batılılaşmanın hayatın her alanında başat ögeye dönüştüğü Cumhuriyet döneminin aydın sınıfıyla, mistik yönelim bağlamında ayrışma yaşayan önemli bir şair de Fazıl Hüsnü Dağlarca'dır. Fazıl Hüsnü şiirinin imge dünyasına ait temel izlekler; onun şiirinin mistik arka plandaki gönderimleri, bir takım felsefî metinler ve referanslarla karşılaştırma olanăg 1 sunacaktır.
\end{abstract}

Anahtar Kelimeler: Fazıl Hüsnü Dağlarca, Mistik, Tanzimat, Çocuk ve Allah, Varoluşsal.

\footnotetext{
${ }^{1}$ Makale Geliş/Kabul Tarihi: 15.07.2020 / 18.09.2020

Künye Bilgisi: Şamlıŏlu, K. (2020). Fazll Hüsnü Dağlarca Şiirinde Mistisizm ve Sezgi. Kahramanmaraş Sütçü İmam Üniversitesi Sosyal Bilimler Dergisi, 17 (2), 842-850. DOI: 10.33437/ksusbd.769984
} 


\title{
Mysticism And Intuition In The Poems Of Fazl Hüsnü Dağlarca
}

\begin{abstract}
The Tanzimat process, which is one of the important crossroads of westernization, also forms the basis for the enlightened profile to present itself with its literary identity. The crisis of the values that have been passed down from generation to generation for centuries has spread to the field of literature, and the confusion of the Tanzimat intellectual has made the understanding of literature, especially poetry, ambiguous. This ambiguity stems from the fact that one of the means of domination of the West on the East is literature. Tanzimat intellectuals will not be able to give up traditional poetry easily while turning towards French poetry, which he sees as new, modern and contemporary. While loading new epistemic areas from the West, an area of resistance is formed that will protect its own concepts from tradition. While all these are happening, embracing Western values emerges with a certain level of positivist reflex, and defending tradition manifests itself with the reflex of mysticism at its opposite end. While the concepts of Islamic thought are dispersed through the poetry tradition, the existence of this situation in the Tanzimat intellectual opens the door to new concepts in accordance with the modern way of thinking. When we come to the Republic period, this situation appears as a problem of returning to its source. The intellectual who has problems with the data of modernity tends again to existential values.
\end{abstract}

Another important poet who experienced a separation in the context of mystical orientation with the intellectual class of the Republic period, when the westernization that started with the Tanzimat turned into the dominant element in all areas of life, is Fazıl Hüsnü Dağlarca. Basic themes belonging to the imagery world of Fazıl Hüsnü poetry; the references of his poetry in the mystical background will allow comparison with some philosophical texts and references.

Keywords: Fazıl Hüsnü Dağlarca, Mystic, Tanzimat, Çocuk ve Allah, Existential.

\section{GİRiş}

Türk şiirinin modernleşme evresinde kaynağına dönüş problemi, gelenek ve varoluşsal kodlara bağlı olarak tahayyül edilmelidir. Klasik edebiyattan kopuş, 
retorik açıdan bir dönemin kapandığına işaret eder. Tanzimat ile başlayan süreçte ise Batı merkezli düşüncenin edebî düşünce sahasına girişi, aklı referans alan şiir kurma çabasını gözler önüne serer. Özellikle Ziya Paşa'nın Terci-i Bend'i, Sadullah Paşa'nın Ondokuzuncu Asır' 1 ve Akif Paşa'nın Adem Kasidesi tam da o süreçte ortaya çıkıp yayılan pozitivist eğilimler tarafından tahrip edilen klasik edebiyatın sigaya çekilmesi, dahası yüzleşmesi ve bu yüzleşmeden mütevellit bir yokluk hissine sığınmasının somut metinleri olarak kendini gösterir.

Ak1l temelli bir mukayesede; denilebilir ki Kant felsefesinin noumene'in alanını kavranamaz oluşu idrakiyle kapatması, fenomenler âlemini kuşatmak ve açmak suretiyle aklın ve zekânın merkeziliğini vurgular: "Descartes ve Kantçılık hakikat araştırmalarında zekânın türlü şekillerde kullanılmasını denemişler... Kant'ta zekâ noumene'in tanınmaz oluşu (inconnaissable) çıkmazına saplanınca felsefenin hakikat davası batıl bir dava hâline gelivermiştir" (Topçu, 2011: 43). Akıl merkezli bu arayışın son dönem Osmanlı aydınlarında güçlü şekilde yer edindiği yadsınamaz bir gerçektir. Bu eserlerin tematik incelemeleri yapıldığında ya filozofun evren karşısındaki sorgulayıcı tavrı ya da bir bilim adamının akla, tecrübeye ve imana karşı derin bir imanı (Kaplan, 2011: 75) sezilir. Elbette edebiyat metinleri bağlamında, söz konusu felsefî yaklaşım tarzının edebî metinler üzerinde de problem alanı doğurduğunu söylemek yanlış olmaz. Özellikle modernleşme dönemi örneklerinde, şiir eksenli söz konusu metinler, buna örnek sayılabilir. Şinasi'nin Münâcât'ındaki;

"Vahdet-i zâtına aklımca şahâdet lazım

Can ü gönlüme münâcât ü ibâdet lâzım” (Kaplan, 2011: 32).

beyti ile vurgulanan akıl referanslı iman tezi, ilerleyen dizedeki

“Ne dedim tövbeler olsun bu da fi'l-i şerdir” (Kaplan, 2011: 32)

ifadeleriyle birleşerek retorik problem alanında yaşanılan ani dönüşümün işaretlerini verir. Dolayısıyla her ne kadar retorik bağlamda maddeci tavır alış varsa da kültür ve gelenek bağlamında gelenekten tam bir kopuş mümkün olmamıştır. Bu kopuş ve bağlanış ikilemi ontolojik problem alanlarını işaret eder: "Acaba bu yeniden kurulum bir öncekini yıkarken, metni organik bir kaynağa geri dönüş olarak yollarını kapatarak $\mathrm{m} ı$ bunu yapar; yoksa sürdürülebilir organik bağlar yoksa sürdürülebilir retorik bağlar her türlü yeniden yapılanmaya karş1 dirençli olarak mı kalır?" (Polat, 2018: 52). Bu sorularla birlikte denilebilir ki Tanzimat'la başlayan Türk şiirinin retorik sahası kopuş ve dönüş ikileminde söylemini sürdürür. Dolayısıyla Türk şiiri sorunsal alanını retorik düzlemde yaşamış olsa da varoluşsal kaynağa dönüş zor olmayacaktır. Bu minvalden olmak üzere Tanzimat düşüncesinin önde gelen mütefekkirlerinden Ahmet Midhat'in 
bile düşünce dünyasının felsefî arka planında, köklere dönüş çağrısı niteliğinde ifadeler duymak mümkündür (Şamlıoğlu, 2020: 100).

$\mathrm{Bu}$ dönüşün her zaman mümkün görüldüğü, bağlam noktasında sürekli bir temas hâli yaşayan şairlerden biri de Fazıl Hüsnü Dağlarca'dır. Şairin Havaya Çizilen Dünya, Çocuk ve Allah eserlerinden sezgici tutumunu devam ettirdiği diğer şiirlerine kadar, başat temayülü mistisizmdir. Dağlarca'nın şiirinde sessiz bir derinliği çocuk imgelemiyle görmek mümkündür. Şair kendi dünyasında oluşturduğu çocuk imgesiyle kâinatın en ücra noktalarına bir yolculuğu kurar iken aynı zamanda metafizik bir düzlemi de inşa etmiş olur. Cumhuriyetin baskın metinleri karşısında Dağlarca'nın şiirlerinde içe dönük bir yapı kurma çabası onun nevi şahsına münhasırlığı ile ilgilidir. Dönemiyle yaşadığı aykırılık bir anlamda şaire varoluşsal kodlara dönüş imkânı sağlar. Bu dönüşün ilk çağrısı, Murat Belge (2018: 302)'nin de şiirlerine enerjisini veren güç olarak nitelediği mistisizmdir: "Fazıl Hüsnü, 'kendini merak eden' bir şair. Çözemediği, belki başa çıkamadığı şeyler var. Bunların üstüne şiirleriyle gidiyor, ama bu bir uzlaşma ya da bir 'aydınlanma' ile sona eren bir yaşantı da olmuyor, olamıyor. Dolayısıyla orada hep o 'sır' var. 'Mistik' dedik. 'Mistisizm' ile 'mister' arasında bir akrabalık vardır. $O$ erişilemeyen ve çözülemeyen şeyin varlığı bu erken dönem şiirlerinin enerjisini sağlıyor, sanıyorum.” Fakat şunu söylemek mümkün ki Dağlarca şiiri, mistisizmini, birer mukayese örneği olarak Necip Fazıl şiirinin temel kaynağını ve mistik şiir imgelerini besleyen kimi dinsel içerikli insan Allah ve kâinat algısından farklı seyreder. Başka bir deyişle Dağlarca, mistisizmi şiiriyet bağ 1 estetikten yana kurulmuş bir dekorda; içselleştirilmekten çok evren karşısında şairin seküler dünya tasavvuru olarak görülebilir.

Şairin evren karşısındaki meraklı tutumu, bir çocuğun tabiatı anlamlandırmaya çalışmasındaki saf derinlik ile benzerlik gösterir. Dağlarca'nın şiirinde çocuk imgesi anne karnındaki varoluşa bir dikkat kesilme ve kâinatın manevi anlamına dinginlikle süzülme olarak da görülebilir. Tanzimat'ın ilk şairlerinde gördüğümüz sorgulayıcı tavır, Dağlarca'nın şiirinde mistisizm aracılığıyla söylem genişliği bulur. Şairdeki mistisizm tasavvufi kavramlar düzleminde kurulmamış olsa da kâinatın sessizliği ve uyumu üzerinden Allah ve birlik ilkesiyle ilişkili olarak değerlendirilebilir. Sözgelimi Bu Eller miydi şiirinde imgesel açılımlarla mistik duyuş yaşayan Dağlarca'nın sezgisel tutumu göze çarpar:

"Bu eller miydi masallar arasindan

Rüyalara uzattığım bu eller miydi.

Arzu dolu, yaşamak dolu,

Bu eller miydi resimleri tutarken uyuyan.” (Çocuk ve Allah, 2011: 12). 
Burada şairin "el" kelimesiyle "masal" ve "rüya" ile kurduğu ilişki varlık düzeyinde duyu organı işlevi gören maddesel düzeyden, deneyüstü formlarla inşaya çalıştığ 1 temas olarak yorumlanabilir. Paul Valery (2020: 192)'nin "saf şiir” i tanımlarken duyu ötesi bir alana işaret etmesi, şairin bilinç dışı bir yönelimle rüya ve mistik alana açılımına kaynak göstermektedir: "Bağımsız şiirsel duygu hissi ve takdire şayan bir özelliği sayesinde diğer insani duygulardan farklıdır: Bize bir sanrı hissi veya bir dünyanın sanrısını verir (bu dünyada olaylar, imgeler, varlıklar ve şeyler sıradan dünyayı dolduran şeylere benzese de bütün hissiyatımızla samimi bir ilişki içerisindeyiz.) Bilinen nesneler ve varlıklar bir şekilde - bu tabir için beni affederseniz eğer - müzikalize olmuştur. Bunlar birbiriyle rezonansa geçip bizim hissiyatımıza göre ayarlanmış gibi gözükmektedir. Böyle tanımlanınca şiirsel dünyanın rüya hâli, en azından bazı rüyalar tarafından üretilen hâle yakınlık kurar.” Çünkü şiir bilinmeyen bir müphemlik duygusunu forma aktarabilmektir. Bu bakımdan Dağlarca'nın denediği şey, şiir objesi olan dış dünyanın reel gerçekliğini biraz esnetebilmektir.

İçe dönük temas hâli, arkaik düzlemde mistik bağlamda duyu ötesi âleme yöneliş, şairin kaynağa dönüş formunu yeniden gündeme getirir. Çünkü varoluş kodlarına açılım, yaratılıştaki töze inme imkânı sağlar. "Dağlarca kendine büyük bir dünya kurmaya çabalamış bir şairdir. Mistisizm onun şiirinde bir aşamadır. Dünyaya bakış açısı değil, dünyaya bakmaktan doğan bir coşkudur." (Bayıldıran 2009: 230). Bu Eller miydi şiiriyle devam eden dizelerde şairin;

"Ve her şeyden ve her şeyden sonra

Bu eller miydi Allah'a açılan!” (Çocuk ve Allah, 2011: s. 152).

dizeleri, varlık formunda duyu işlevi gören "el"in "Allaha açılan" ibaresiyle tamamlanmas1, maddî âlemden mistik âleme "el" metaforuyla açılım gösterme adeta iki âlem arasındaki perdeyi bu metaforla aralama şeklinde yorumlanmalıdır. Çünkü şairin "masallar arasından/Rüyalara uzattığı" eller, bu defa "Allah'a" yani varoluşun aslî unsuru olan cevhere uzanır. Dolayısıyla Dağlarca'nın şiirinde varlık âleminden sanrılar dünyasına geçiş, "her şeyden sonra/Allah'a açılan" fenomenin ötesine geçme imkânına işaret eder. Dağlarca'nın var oluş karşısındaki dinginliği ve imanı onun çocuk saflı̆̆ında kabullenişini ortaya koyması bakımından dikkate değerdir.

Şiirini duyular âleminin ötesine taşıyan Fazıl Hüsnü Dağlarca'nın, içe dönük bir yapı kurma konusunda poetik tutumunu inceleyen Şükran Kurdakul (2005: 188) özellikle şairin ilk dönem şiirlerine şöyle bir yorum getirir: "Tek olarak insanın evren karşısındaki şaşkınlığını, yalnızlığını, korkularını ölüm gerçeğine karşın yaşarken duyduğu bunalımları, doğasal görkemin yansımalarını işlemeye çalıştığı içe dönük şiirler.” Dağlarca'nın bilinç dışı temayülle etkileşim içerinde olması, ontolojik sorgulamalara kapı aralarken şiirinde ortak bilinç dışına yani 
arketiplere başvurması olarak kendini gösterir. Söz gelimi Toprak adlı şiirinde arkaik göndermeler, ilahi güç ve toprak unsurunu birlikte kullanma imkânı sağlar:

"Var Allah’ım bir şey bu toprakta

Ağaçlar büyür ansızın.

Bitmez tükenmez sular çılıyor

Ki kalbe lahzalar taşımakta." (Kurdakul, 2005: 195)

Şair, kâinattaki sistematik düzenin işlemesini "Var Allah'ım bir şey bu toprakta" dizesindeki anlam derinliği ile karşılar ve bu işleyişin kavrama düzeyini toprağa yönelerek yapar. Çünkü toprak, sadece üzerinde yaşanılan kara parçası olarak değil aynı zamanda varoluşun kaynağı, tüm yaşanmışlığıyla toplumsal hafızadır. Toprak aynı zamanda insana aidiyet hissi vermesi ve doğurganlık özelliğiyle anne arketipini simgeler. Bu bağlamda "Toprak Ana" imgesi, varoluşsal töze inme imkânı oluşturma derinliğine sahiptir. Dağlarca'nın şiirinde ağaçların büyümesini ve suların çıkmasını "toprak" kelimesiyle ilişkilendirerek sunması, yaşamdaki senfoniyi harekete geçiren aslî unsura bir anlamda gönderme olarak görülebilir. Çünkü şair kâinattaki düzeni sağlayan ana formu "toprak" kelimesi ile açımlarken bu yönelimi yine Allah'a bağlanarak gerçekleştirir. Fazıl Hüsnü Dağlarca varlık düzeyinde yaratılıştaki cevherin nihai bulgusunu Allah’a yönelerek güçlendirir. Bu durum, şiir-gelenek ilişkisi çerçevesinde izah edilen poetik bir yönelime benzeşmekle beraber ve denilebilir ki Cumhuriyet devri Türk şiirinin varoluşçu ve Marksist prensipli gelişen negatif poetikalarından da ayrı bir şiir tarzına işaret eder. Çünkü materyalist temelli bir içselleştirmenin sonucu olarak örneğin Orhan Veli'de "böcek" ne kadar deneysel bir şiirsel imaj durumuna taşınmışsa Dağlarca'da "toprak" bir o kadar deneyüstü bir şiirsel retorik kazanma çabası içinde olmuştur. Başka bir deyişle Orhan Veli'de "böcek" kelimesi bilgi nesnesiyle kurulan metafizik dışı (somut/konkre) ontolojik yer değiştirme, bilgi nesnesinden hareketle şairin evren tasavvurunu indirgemeci hâle getirirken; Dağlarca, “toprak”la söz konusu ontolojik yer değiştirmeyi göksel bir hakikate, yani metafizik bir idrak biçiminin sınırlarına yaklaştırır.

Fazıl Hüsnü Dağlarca varoluşsal düzlemde sorgulamasını yaptığı hayatın ilk nedenlerine varma hususunda önemli bir mistik deneyim oluşturur. Dağlarca'nın şiir yolculuğu kendi yolculuğunun da başlangıcıdır. "Şiir serüveni insan serüveninin ayrılmaz bir parçasıdır. İnsanın varoluşundan bu yana - yalın anlamda antolojisi olabilir - evren karşısında duyduğu hayret onu alıp götürür." (Hızlan, 2010: 78). Denilebilir ki Dağlarca'nın poetikasını belirleyen etken, sezgici bir duyuşla bir çocuğun evren karşısındaki sorgulayıcı tavrı ve en sarih duygularla yaratılıştaki cevhere ulaşma arzusudur. Allah'a ve Bize Dair şiirinin şu dizelerinde bu dönüş arzusu görülür: 
“Allah ne kadar büyüktür,

Ekinlere güneş verir çocuğum.

Beni mavi sabahlara devreder,

Mavi güller gibi uykum.” (Çocuk ve Allah, 201: 124).

Şairin kâinat karşısında içe dönük kavrayışa girişmesi bu şiirinde de varoluşsal nedeni anlama ve kaynağa yönelme izleğini sürdürür. Kozmik düzenin sağlayıcısı olarak Allah'a yapılan atıf, alt dizede şairin "ben"liğini oluşturan töze yönelme, içsel deneyim ve dışsal gözlemle şiirsel düzeyde aktarım imkânı sağlar. Bergson (2011: 52) metafizik tanımına yönelirken "ben"liğin süresi içerisinde, yine "ben" tarafından edinilecek mutlak bilginin mümkün olduğu görüşü, Dağlarca'nın poetikasında içsel deneyimle aslî unsuru kavrama çabası olarak karşılık bulur. Bu durum varlığını yaratıcıda bulan şairin; "Beni mavi sabahlara devreder" dizesiyle, uzam ve zaman kavramının sürekliliğine ve ezeli-ebedi varlık düzeyinde duyumsanan bütün olguların tek bir ilahi güçte birleşmesi anlamına gelir. Yani Dağlarca'nın poetik tutumu kaynağa yönelme ve aslî unsuru bulma yönündedir. Bu ise "ben”liğin kendi varlığının ötesinde içsel duyuşla çeşitli vadilere inerek mutlak hakikate ulaşma arzusundan kaynaklanır. Şair ve dünya arasındaki bağlantının sezgi boyutuyla ilişkili olan bu durum, Dağlarca şiirinin mistisizme eğilimini, tasavvufi anlamda tam olarak karşılamasa da gelenekle sınırlı irtibatı bakımından iddia edilebilir ki geleneğin çok dışında birakmaz.

Dağlarca şiirinin içsel deneyim ve duyuş tarzını yorumlayan Cemal Süreya (2015: 63) benzer bir konuya dikkat çeker: "Sanki Fazıl Hüsnü'nün şiirlerinde zekâ, yukardan aklın bol pencereli, ama ufak odasında dinlenirken, aşağıdan vücudun, yani doğanın kan damarlı, karanlık, karmaşık sokaklarında dolaşır...". Dolayısıyla Dağlarca şiirinin kalkış noktası, bilinç dışı bir temayülle kozmik düzeni harekete geçiren mutlak güce ulaşma arzusudur. Buna ulaşmak için şairin evrensel deneyim dediğimiz ortak bilinç dışına ait imgelere başvurması, soyut şiir örneği olabilecek duyu ötesi bir âleme işaret eder.

\section{SONUÇ}

Tanzimat ile başlayan modernleşme evresinde Türk aydınının yaşadığı önemli bir husus, kaynağına dönme problemidir. Çünkü gelenekle bağı zayıflatılmış Türk şiirinin doğası ve beslenme kaynakları, klasik metin ve düşünce sistemlerinin Tanzimat'a kadar yoğun münasebeti ile şekillenir. Adını Tanzimat'tan sonra mistisizm olarak kabul ettiren kavram, metafizik bağlamında sanatsal içeriğini daima İslâmî bir estetik kaygıyla harmanlar. Hâlbuki Şinasi, Namık Kemal ve Hamid gibi edebiyat düşüncesine mutlak tesir bırakmış 
aydınların, batılı söylem düzeyinde kurdukları şiir dilinde ikilem içerisinde kaldıkları yadsınamaz bir gerçektir. Deneyüstü/sezgi olarak tanımlanan epistemolojik eğilimin şiir sanatı üzerindeki kaynak problemini, Osmanlı düşüncesindeki pozitivist genel moda ekseninde baskılamaya çalışan söz konusu Tanzimat öncülerinde olduğu gibi Cumhuriyet döneminde de şiir adına deneyüstü/sezgisel kaynaklar çoğunluklu olarak ötelenmiştir diyebiliriz. $\mathrm{Bu}$ aydınlar her ne kadar batıcı bir evrede ve Fransız pozitivizminin çok güçlü tesirlerinin olduğu bir yüzyılda şiir kuruyor olsa da kendi içyapılarındaki kültür ve gelenek kopması şiirlerinde ani dönüşe firsat verir. Tanzimat'n yenilikleri Cumhuriyet ile ayyuka çıkmış olsa da içsel arayış ve duyuşa sahip aydında kaynağına dönüş problemi her zaman dinamik kalır. Bu, Batı'nın Doğu üzerindeki tazyikinden dolayı gelenek ile doğrudan buluşmanın önüne set çekerken mistisizmi geleneği meşrulaştıran bir ögeye dönüştürür. Böylece Tanzimat sonrası Türk aydınının yaşadığı en önemli çelişkilerden biri olan Doğu ile Batı'ya sıkışmışlıkta çıkış noktası geçmişe rücu etmenin bir yolu olarak Batı mistisizmine sığınmak veya en azından ondan bir şekilde faydalanmak biçiminde kendini gösterir.

İşte tam da bu noktada Necip Fazıl, Âsaf Hâlet Çelebi gibi şairlerin yanı sıra Fazıl Hüsnü Dağlarca da gelenek ile buluşmanın bir yolu ve aracı olarak mistisizme sığınmış gibi görünür. Necip Fazıl'ın geleneğe doğrudan teması, Âsaf Hâlet Çelebi'nin de Hint mistisizmine yönelen şiiri bir tarafa bırakılırsa kültür ve gelenek açısından beslendiği kaynağa Batı mistisizmi üzerinden dolaşarak yönelim gösteren devrin en önemli şairlerinden biri Fazıl Hüsnü Dağlarca'dır. Poetik olarak içsel bir duyuşa sahip yazarın sezgisel üslupla kurduğu şiirde, dönem ve zamanının ötesine geçmesi varoluşsal değerleri mistik duyuşla kavrama çabasından ileri gelir. Dolayısıyla gelenekle bağın kesildiği bir yüzyılda Dağlarca şiirinin sezgi temelli sancıları, adı seküler olarak konulmuş bir çağın yazgısına terk edilmiş şairin çığlıklarıyla yankılanır. Böylelikle Dağlarca, poetik ilerleyişini şiir bakımından lirizmle bağları kesilmemiş bir kaynak ihtiyacının daha soyut yanıyla rahatlıkla ilişkilendirilebilir.

\section{KAYNAKÇA}

Bayıldıran, Sabit Kemal (2009), Dağlarca: Kâinatla Yaşıt Çocuk, Fazıl Hüsnü Dağlarca, Kültür ve Turizm Bakanlığı Yayınları, Ankara.

Belge, Murat (2018), Şairaneden Şiirsele Türkiye'de Modern Şiir, İletişim Yayınları, İstanbul.

Bergson, Henri (2011), Metafiziğe Giriş, Paradigma Yayınları, İstanbul.

Dağlarca, Fazıl Hüsnü (2011), Çocuk ve Allah, Yapı Kredi Yayınları, İstanbul. 
Hızlan, Doğan (2010), Edebiyatımıza Dipnotlar, Yap1 Kredi Yayınları, İstanbul.

Kaplan, Mehmet (2011), Şiir Tahlilleri 1, Dergâh Yayınları, İstanbul.

Kurdakul, Şükran (2005), Çağdaş Türk Edebiyatı 3, Evrensel Basım Yayınları, İstanbul.

Polat, Adem (2018), İkinci Yeni Şiirinin Felsefi Kaynakları, Kesit Yayınları, İstanbul.

Süreya, Cemal (2015), Şapkam Dolu Çiçekle Toplu Yazılar 1, Yapı Kredi Yayınları, İstanbul.

Şamlıoğlu, Kemal (2020), Tanzimat Yeniliğinin Retorik Problemleri, Kesit Yayınları, İstanbul.

Topçu, Nurettin (2011), Bergson, (Haz. Ezel Ayverdi - İsmail Kara), Dergâh Yayınlar1, İstanbul.

Valery, Paul (2020), Şiir Sanatı, (Çev. Ahmet Ölmez), KTB Yayınları, İstanbul. 